\title{
Biologia de anofelinos amazônicos 1 - Ciclo biológico, postura e estádios larvais de Anopheles darlingi Root 1926 (Diptera: Culicidae) da Rodovia Manaus - Boa Vista(1)
}

\author{
Joselita M. Mendes dos Santos ( $\left.{ }^{2}\right)$ \\ Eucleia Primo B. Contel (') \\ Warwick E. Kerr (4)
}

\begin{abstract}
Resumo
Os estudos de laboratório sobre a biologia de $\mathbf{A}$. darling demonstraram que o ciclo biológico de ovo a adulto se faz, em média, em 15.6 dias e com uma taxa de sobrevivência de $57 \%$ quando criados de 25 a $28^{\circ} \mathrm{C}$. O número médio de ovos por postura foi de $110 \pm 50,61$ e eclodiram em média $83,31 \pm 48,21$, com um tempo médio para eclosão de dois dias. O tempo de desenvol. vimento de cada estádio imaturo apresentou variaçōes. O 2. e 3. 'estádios larvais apresentaram um tempo de desenvolvimento menor do que o $11^{\circ}$ e $4 i^{\circ}$ estádios.
\end{abstract}

\section{INTRODUÇÃO}

Anopheles (Nyssorhynchus) darlingi é considerado o principal vetor da malária humana, sendo responsável pela sua transmissão em todo interior do País (Rachou, 1958; Ferreira, 1964). Alguns estudos foram feitos sobre a criaçăo e manutenção desta espécie em laboratório, mas até o momento não foram bem sucedidos (Barreto \& Coutinho, 1943; Bates, 1947; Freire \& Faria, 1947). Quando esta colonização for obtida em laboratório, aumentará as possibilidades de estudo do comportamento e da constituição genética dessas populações.

Zulueta \& Bates (1948) estudaram o comportamento de oviposição de Anopheles darlingi e verificaram que fatores físicos como orientaçăo espacial, luz e obstáculos são de grande importância na seleção do local de oviposição no laboratório. A dinâmica de uma população desta espécie, durante um ciclo anual foi estudada por Hayes \& Charlwood (1979) numa área endêmica de malária no Amazonas, obser- vando um aumento da população e maior incidência de malária na estação seca. A. darlingi apresenta diferenças comportamentais em diferentes áreas, sendo possivelmente resultantes de variações genéticas interpopulacionais (Charlwood \& Hayes, 1978)

Este trabalho visa a estabelecer o tempo de desenvolvimento de cada um dos estádios imaturos de Anopheles darlingi, bem como determinar o grau de fertilidade das fêmeas.

\section{MATERIAL E MÉTOdos}

$\mathrm{Na}$ execuçãc deste trabalho, utilizamos a espécie Anopheles (Nyssorhynchus) darlingi proveniente dos $\mathrm{Km} 137$ e Km 182 da BR 174 (Estrada Manaus-Boa Vista, Fig. 1) .

$\mathrm{Na}$ identificação do material, foram utilizadas concomitantemente as chaves sistemáticas de Corrêa \& Ramalho, 1957 (apud Resende, 1969) de Gorham et al. (1967) e de Cova-Garcia (1961).

As coletas foram feitas mensalmente de setembro de 1977 a setembro de 1978 , no período noturno, entre 18 e 24 horas, nas residências e em plantas ao redor das casas. Os mosquitos eram localizados com o auxilio de uma lanterna, capturados com um aspirador e transferidos para uma gaiola telada com cerca de $20 \times 20 \mathrm{~cm}$, na qual eram trazidos para o laboratório.

O método de criação de anofelinos em laboratório foi baseado em Freire \& Faria (1947),

(1) - Parte da Dissertação de Mestrado apresentada pelo primeiro autor em 1979 ao Curso de Pós-Graduaçã̃o do Instituto Nacional de Pesquisas da Amazônia e Universidade do Amazonas.

(2) - Instituto Nacional de Pesquisas da Amazônia, Manaus.

(3) - Faculdade de Medicina de Ribeirão Preto, SP.

(4) - Universidade Federal do Maranhăo, São Luís. 


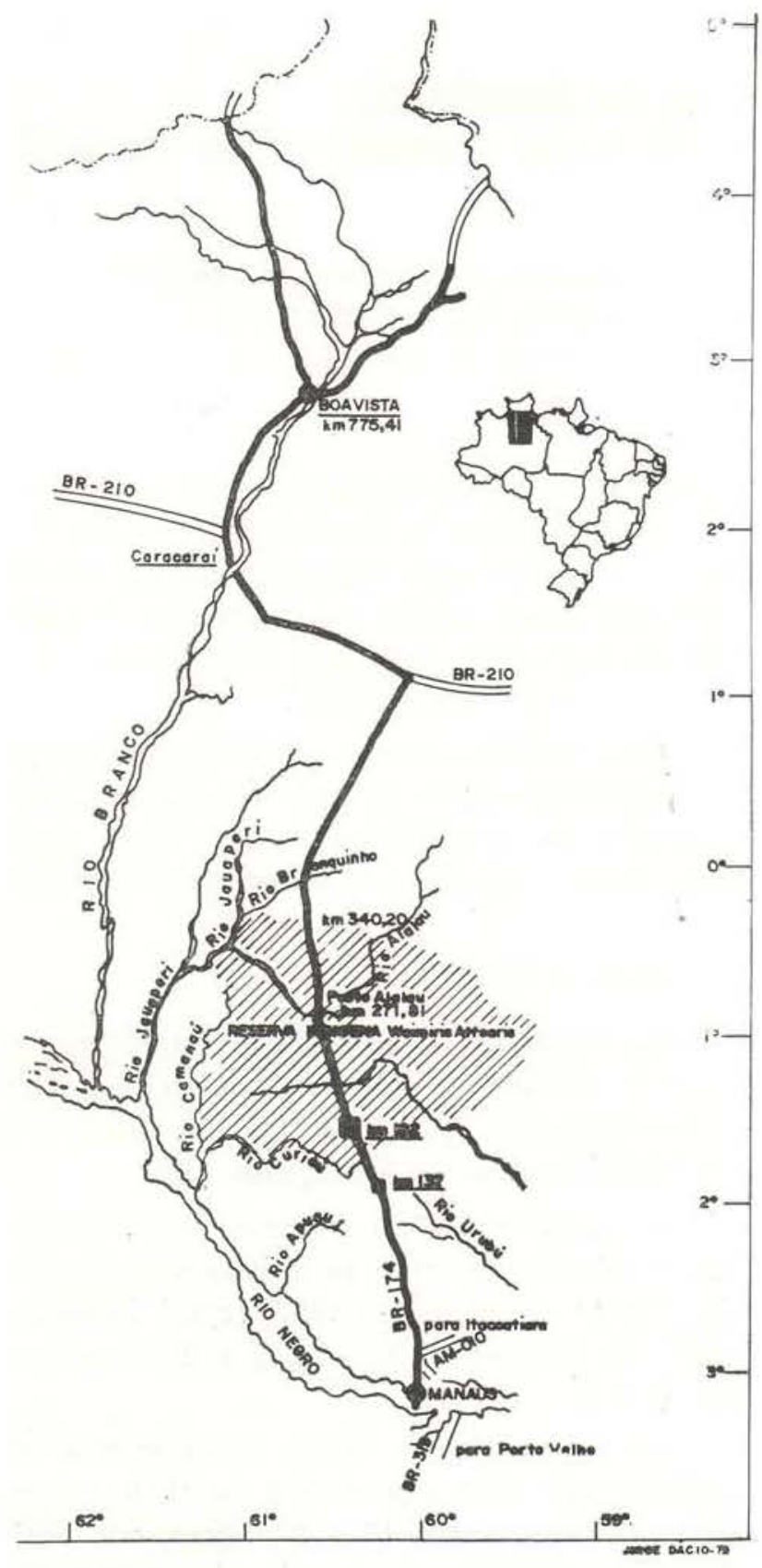

Fig. 1 - Mapa da região de estudo, com indicação da área de coleta ( 圆).

Gerber (1970) em Rabbani et al. (1976) com algumas modificações. As fêmeas eram postas a desovar individualmente em copos plásticos com cerca de $50 \mathrm{ml}$ de água destilada e com a parede interna forrada com papel de filtro, para evitar que os ovos se dessecassem quando aderissem à superfície. Cada copo era coberto com tecido de malhas bem finas, preso por um elástico, no qual havia um orifício preenchido com chumaço de algodão, por onde era cclocada a fêmea.

Ocorrida e eclosão dos ovos, cerca de 24 a 72 horas após a postura, as larvas eram contadas e por meic de um conta-gotas, transferidas para um copo contendo água destilada, com a parede interna revestida com papel de filtro e coberto com tampa de plástico. O copo que continha a fêmea mãe era observado por um período de três dias e todas as larvas recém-eclodidas eram transferidas para um outro copo e computadas no número total de eclosão. Em seguida, era colocado cerca de $1 \mathrm{ml}$ de alimento fresco, discriminado adiante. Após 36 horas, as larvas eram transportadas para bacias esmaltadas, previamente esterilizadas, medindo $29 \times 17,5 \times 6 \mathrm{~cm}$ e contendo $350 \mathrm{ml}$ de água destilada. As bacias eram cobertas com tampas de acrílico transparente.

Foram testados vários tipos de alimento para estabelecer aquele que possibilitasse meIhor desenvolvimento das larvas. A princípio, utilizamos uma mistura de pó de fígado com ração de coelho, na proporção de 1:1, $2 \%$ em água. Para obter-se maior quantidade de ciliados, acrescentamos extrato de levedura a essa mistura. Testamos também somente o pó de fígado com ração de coelho e depois, cada um desses individualmente.

Posteriormente, face a melhores resultados obtidos, passamos a usar uma mistura de farinha de pão torrada, germe de trigo e farinha de peixe. 2:2:1, $2 \%$ em água, sendo essa ministrada às larvas a cada 48 horas.

As larvas de $1 .^{\circ}$ e $2^{\circ}$ estádios eram alimentadas com tal mistura preparada na hora; para larvas de $3 .^{\circ}$ e $4^{\circ}$ estádios, a mistura era preparada com 4 a 5 dias de antecedência, para permitir a formação de ciliados necessários à boa alimentação e, conseqüêntemente, ao bom desenvolvimento das laivas. Os adultos eram alimentados com solução açucarada (sacarose) a $10 \%$. A água das bacias era trocada a cada dois dias com a ajuda de uma pipeta e após, o alimento era dado às larvas. Quando essas empupavam, eram recolhidas e colocadas nos copos com água, para eclosão. 
Durante a manutenção desses mosquitos, foram feitas observações diárias, a fim de estabelecer-se o tempo de desenvolvimento de cada estádio imaturo através das ecdises. Para isso, foram retiradas 10 larvas de $1^{\circ}$ estádio recentemente eclodidas de 10 posturas (total de 100 larvas) as quais foram colocadas individualmente nos copos com tampas de plástico contendo água destilada e alimentadas como já foi descrito.

Toda a criação dos anofelinos foi realizada no interior de um insectário medindo $3 \times 3 \times 3 \mathrm{~m}$. com temperatura variando entre 25 e $28^{\circ} \mathrm{C}$.

\section{Resultados}

De acordo com Boyd et al. (1935) citados em Barreto \& Coutinho (1943), dois fatores são de grande importância para o desenvolvimento das larvas: fornecimento de alimentação abundante e manutenção da temperatura a nível constante e ótimo, sendo que o primeiro é de importância vital.

Pártindo dessa premissa, procuramos adaptar esses dois fatores às melhores condições para o desenvolvimento dos anofelinos; entretanto, os resultados obtidos quando se usou o alimento feito com uma mistura de pó de fígado, ração de coєlho e extrato de levedura, não foram animadores, em virtude da contaminação por fungos que atacavam as larvas, principalmente nos dois últimos estádios. Quando as larvas empupavam, não havia a emergência total dos adultos, que ficavam presos à exúvia pupal como acontece, por exemplo, quando a alimentação é imprópria (Freire \& Faria, 1974). $\mathrm{O}$ mesmo aconteceu quando se usaram esses ingredientes individualmente. Empregando o alimento que se apresentou mais apropriado (descrito em Material e Métodos), a evolução de $A$. darlingi, de ovo até adulto se fez, em média, em 15,6 dias ( $\mathrm{Tab}$. I).

Das 229 posturas obtidas em laboratório resultaram num total de 25.214 ovos, sendo que houve uma variação de 10 a 246 ovos por fêmea, com uma média de 110 ovos ( $D P=50,6$ ) por fêmea (Fig. 2). Na tabela II, pode verificar-se que houve um grande número de fêmeas (33) que botaram uma quantidade de ovos próxima à média de ovos/postura. Pode ainda ser
TABELA I - Tempo (dias) de emergência de adulto após a oviposição, com as respectivas freqüências absoluta e relativa, de Anopheles darlingi, em condiçöes experimentais

\begin{tabular}{ccc}
\hline $\begin{array}{c}\text { Duração em } \\
\text { dias }\end{array}$ & $\begin{array}{c}\text { Número de } \\
\text { observações }\end{array}$ & $\%$ \\
\hline 11 & 1 & 1,75 \\
12 & 6 & 10,52 \\
13 & 6 & 10,52 \\
14 & 8 & 14,03 \\
15 & 11 & 19,29 \\
16 & 10 & 17,54 \\
17 & 5 & 8,77 \\
18 & 2 & 3,50 \\
19 & 1 & 1,75 \\
20 & 3 & 5,26 \\
21 & 2 & 3,50 \\
22 & 0 & - \\
23 & 1 & 1,75 \\
24 & 0 & - \\
25 & 1 & 1,75 \\
\hline \begin{tabular}{l} 
Total \\
\hline 15,6 dias
\end{tabular} & & 100,00 \\
\hline
\end{tabular}

observado, através da mesma tabela, que a freqüência de fêmeas que puseram mais de 180 e menos de 40 ovos diminui abruptamente em relação aos outros intervalos situados entre esses.

Observou-se também que o número de ovos eclodidos por postura teve ampla variação (de 0 a 218 ovos), com uma média de tempo de eclosão dos ovos aproximadamente de 2 dias. Do total de ovos postos (25.214), 6.136 $(24,34 \%)$ não eclodiram, ou seja, a taxa de eclosão foi de $75,66 \%$ (Tab. III).

Comparando-se os resultados da ovoposição apresentados nas tabelas 2 e 4, verifica-se que as médias estão relativamente próximas (110 e 83,31 respectivamente) o que indica uma boa fertilidade dos ovos. Na tabsla III, pode notar-se ainda que o maior número de ovos eclodidos (13.226) foi obtido dois dias após a ovoposição. 


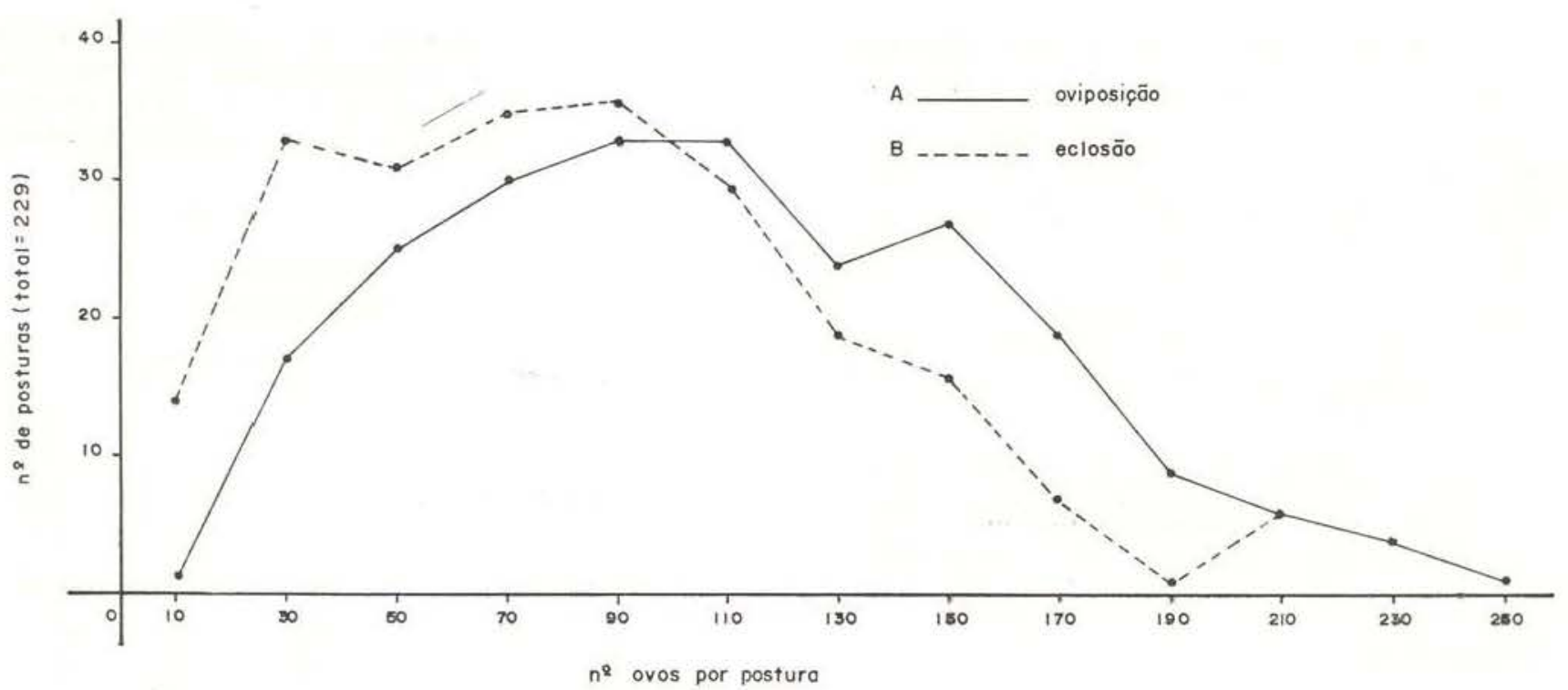

Fig. 2 - Freqüências absolutas do número de ovos postos e eclodidos por postura de Anopheles darlingi, em laboratório.

TABELA II - Freqüências absoluta e relativa do número de ovos postos por postura de Anopheles darlingi, em laboratório.

\begin{tabular}{rrr}
\hline & & \multicolumn{2}{c}{ N. de posturas } \\
\cline { 2 - 3 } Ovos postos & $n \cdot{ }^{\circ}$ & $\%$ \\
\hline $1-20$ & 1 & 0,44 \\
$21-40$ & 17 & 7,42 \\
$41-60$ & 25 & 0,92 \\
$61-80$ & 30 & 13,10 \\
$81-100$ & 33 & 14,41 \\
$101-120$ & 33 & 14,41 \\
$121-140$ & 24 & 10,48 \\
$141-160$ & 27 & 11,79 \\
$161-180$ & 19 & 8,30 \\
$181-200$ & 9 & 3,93 \\
$201-220$ & 6 & 2,62 \\
$221-240$ & 4 & 1,75 \\
$241-260$ & 1 & 0,47 \\
\hline T O A L & 229 & 100,00 \\
\hline
\end{tabular}

$\bar{x}=110$ ovos por postura

DP $=50,61$

$N=229$ posturas

Postura mínima - 10 ovos

Postura máxıma -246 ovos
TABEL.A III - Tempo (dias) gastos para a eclosão, número de ovos postos e eclodidos por postura, com as respectivas frequiências relativass, de Anopheles darlingi, em laboratério

\begin{tabular}{|c|c|c|c|c|}
\hline \multirow{3}{*}{$\begin{array}{l}\text { Dias após a } \\
\text { oviposição }\end{array}$} & \multicolumn{4}{|c|}{ Número de ovos } \\
\hline & \multicolumn{2}{|c|}{ não eclodidos } & \multicolumn{2}{|c|}{ eclodidos } \\
\hline & $\mathrm{n} .^{\circ}$ & $\%$ & n: & $\%$ \\
\hline 0 & 25.214 & 100,00 & 0 & 0 \\
\hline 1 & 22.581 & 89,56 & 2.633 & 10,44 \\
\hline 2 & 9.355 & 37,10 & 13.226 & 52,45 \\
\hline 3 & 6.389 & 25,34 & 2.966 & 11,76 \\
\hline 4 & 6.136 & 24,34 & 253 & 1,01 \\
\hline Total & 6.136 & 24,34 & 19.078 & 75,66 \\
\hline
\end{tabular}

Essas mesmas observações foram feitas, a partir de 100 ovos provenientes de 10 posturas e observou-se que o tempo para a eclosão dos ovos foi de 2 a 3 dias, com uma média de 2,4 dias. O tempo de desenvolvimento de cada estádio apresentou variaçōes, verificando-se que o $1^{\text {19 }}$ estádio sofreu variação pequena: 2 a 4 dias, apesar da duração média alta (2,9 dias) em relação aos outros estádios larvais. $\mathrm{O}^{\circ}$ ? 
TABELA IV - Freqüência do número de ovos eclodidos por postura de Anopheles darlingi, no la. boratério

\begin{tabular}{|c|c|c|c|c|}
\hline \multirow{2}{*}{ Ovos } & \multirow{2}{*}{\multicolumn{2}{|c|}{ eclodidos }} & \multicolumn{2}{|c|}{$\mathrm{N} .^{\circ}$ de posturas } \\
\hline & & & $\mathrm{n} .{ }^{\circ}$ & $\%$ \\
\hline 0 & - & 20 & 15 & 6,55 \\
\hline 21 & - & 40 & 33 & 14,41 \\
\hline 41 & - & 60 & 31 & 13,54 \\
\hline 61 & - & 80 & 35 & 15,28 \\
\hline 81 & - & 100 & 36 & 15,72 \\
\hline 101 & - & 120 & 30 & 13,10 \\
\hline 121 & - & 140 & 19 & 8,30 \\
\hline 141 & - & 160 & 16 & 6,99 \\
\hline 161 & - & 180 & 7 & 3,06 \\
\hline 181 & - & 200 & 1 & 0,44 \\
\hline 201 & - & 220 & 6 & 2,62 \\
\hline TO & $\mathrm{TA}$ & $A L$ & 229 & 100,00 \\
\hline
\end{tabular}

$\bar{x}=83,31$ ovos eclodidos por posturo

$\mathrm{DP}=48,21 \quad " \quad$

$N=229$ posturas

Eclosão mínima - 0 ovo

Eclosão máxima -218 ovos e $3^{\circ}$ estádios apresentaram variação intermediária, com duração média semelhante $\{1,9$ e 2,2 , respectivamente). A fase de pupa teve duração baixa ( 1 a 3 dias) sendo que a duração média desse estádio foi de 1,8 dias (Tab. V).

Comparando-se estes resultados com os apresentados na tabela 6 (considerando-se apenas os 57 indivíduos que sobreviveram até à fase adulta, dos 100 ovos iniciais) verifica-se que não houve diferença significativa quanto ao tempo de desenvolvimento das diferentes tases.

Os resultados da tabela VI mostram o tempo de aparecimento e término de cada estádic de desenvoivimento, com os respectivos graus de mortalidade. A taxa de mortalidade foi de 43, sendo que as porcentagens mais altas $(39,53$ e 37,21$)$ foram observadas nas fases de pupa e larva de 4 o estádio, respectivamente. Larvas de $1^{9}$ estádio apresentaram taxa de mortalidade nula e esta foi muito baixa no $2^{\text {9 }}$ e $3^{0}$ estádios.

O tempo máximo de desenvolvimento de A. darlingi, de ovo adulto, foi de 25 dias e o mínimo de 11 dias, com uma média de 15,6 dias (Tab. I a VII).

TABELA V - Número de indivíduos observados e o tempo de desenvolvimento, em cada uma das fases, de ovo a adulto, sob condições experimentais "

Estádio

\section{$\begin{array}{lllllllllllllll}1 & 2 & 3 & 4 & 5 & 6 & 7 & 8 & 9 & 10 & 11 & 12 & 13 & 14 & \text { observaçōes }\end{array}$}

$\bar{x} \quad$ DP

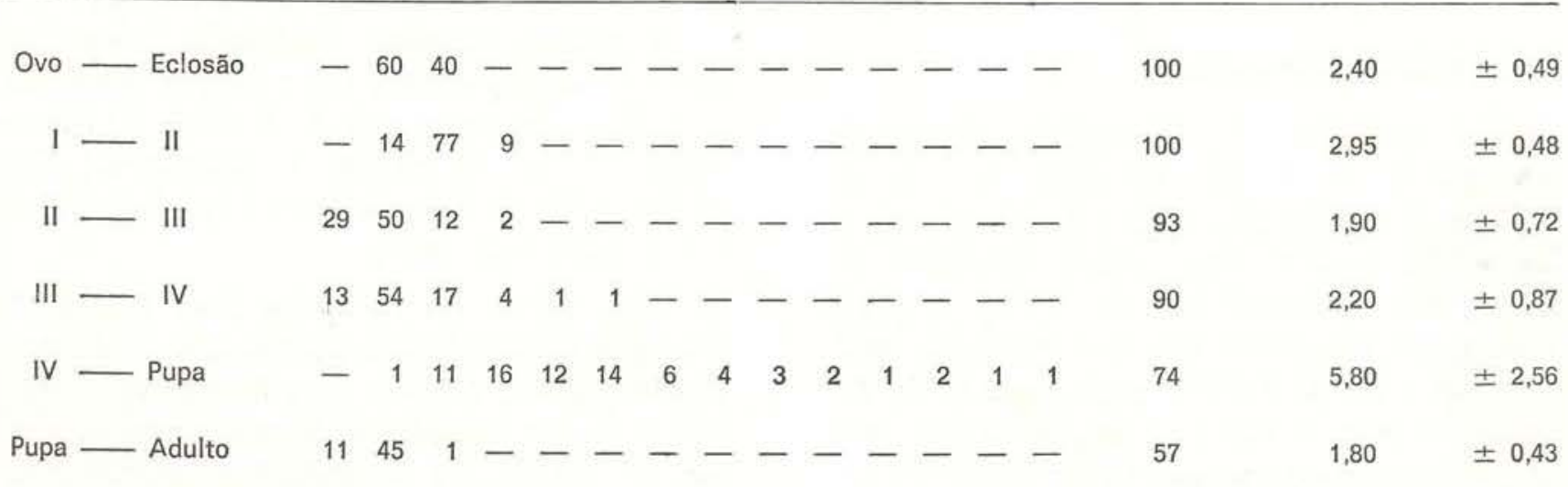

(*) - Levando-se em consideraçäo os indivíduos mortos (43) e sobreviventes (57).

I. IV: estádios larvois. 
TABELA VI - Número de indivíduos observados e tempo de desenvolvimento em cada uma das fases, de ovo a adulto, estudados em condições experimentais "

\begin{tabular}{|c|c|c|c|c|c|c|c|c|c|c|c|c|c|c|c|}
\hline \multirow{2}{*}{\multicolumn{2}{|c|}{ Estádio }} & \multicolumn{12}{|c|}{ Tempo de desenvolvimento (dias) } & \multirow[b]{2}{*}{$\bar{x}$} & \multirow[b]{2}{*}{ DP } \\
\hline & & 1 & 2 & 3 & 4 & 5 & 6 & 7 & 8 & 9 & 10 & 11 & 12 & & \\
\hline Ovo - & — Eclosão & - & 43 & 14 & - & - & - & - & - & - & - & - & - & 2,25 & $\pm 0,44$ \\
\hline 1 & $\longrightarrow \|$ & - & 14 & 37 & 6 & - & - & - & - & - & - & - & - & 2,86 & $\pm 0,58$ \\
\hline II & - III & 23 & 29 & 4 & 1 & - & - & - & - & - & - & - & - & 1,70 & $\pm 0,68$ \\
\hline III & $\longrightarrow$ IV & 11 & 34 & 12 & - & - & - & - & - & - & - & - & - & 2,02 & $\pm 0,64$ \\
\hline IV & — Pupa & - & 1 & 11 & 16 & 12 & 9 & 3 & 1 & 2 & 1 & - & 1 & 4,95 & $\pm 1,91$ \\
\hline Pupa & Adulto & 11 & 45 & 1 & - & - & - & - & - & - & - & - & - & 1,82 & $\pm 0,43$ \\
\hline
\end{tabular}

(*) - Levando-se em consideraçäo apenos o número de individuos sobreviventes (57). I. IV: estádios larvais.

Resumindo os resultados em relação ao tempo de desenvolvimento, em que se consideraram todos os 100 individuos amostrados e somente 57 que sobreviveram até à fase adulta, encontramos as seguintes médias, respectivamente.

Incubação dos ovos
19 estádio larval
$2^{\circ}$ estádio larval
$3^{\circ}$ estádio larval
$4^{\circ}$ estádio larval
Período pupal
TOTAL

$$
\begin{array}{r}
2,40-2,25 \text { dias } \\
2,95-2,86 \text { dias } \\
1,90-1,70 \text { dias } \\
2,20-2,02 \text { dias } \\
5,80-4,95 \text { dias } \\
1,82-1,80 \text { dias } \\
17,00-15,60 \text { dias }
\end{array}
$$

\section{Discussão E CONCLUSÕES}

En! condições de laboratório, obtivemos uma média de duração do ciclo de vida de A. darlingi de 15,6 dias e taxa de sobrevivência até adulto de $57 \%$. Os nossos resultados diferem dos apresentados por Freire \& Faria (1947) que obtiveram um rendimento de $91 \%$ de adultos de $A$. darlingi e um período de desenvolvimento de ovo a adulto de 10 dias. Resultado semelhante a esse último foi obtido em A. albimanus por Baily et al. (1979). Entretanto, os nossos assemelham-se aos de Barreto \& Coutinho (1943) que demonstraram uma taxa de sobrevivência até adulto de $64,6 \%$ e um períodio de evolução de ovo a adulto de cerca de 16 dias. Das quatro espécies do subgênero Nyssorrhynchus estudadas por esses autores, A. darlingi apresentou menor taxa de sobrevivência e mais longo ciclo evolutivo. Paraluppi (1978) estudancio $A$. nuneztovari, obteve uma duração do ciclo evolutivo de 11,9 dias.

Os resultados apresentados parecem indicar que $A$. darlingi se cria com dificuldade em condições experimentais. É possível que haja algum fator influenciando no desenvolvimento ou talvez, as condições no nosso laboratório não são propícias à sua criação.

A grande variação observada quanto ao número de ovos postos (10 a 246) e eclodidos (0 a 218) por postura de $A$. darlingi, foi semeIhante à demonstrada em $A$. nuneztovari $(\mathrm{Pa}$ raluppi 1978) e Culex tritaenorrhynchus (Newson \& Blakeslee, 1957)

Um período de 48 horas para incubação dos ovos é considerado normal nos anofelinos (Rachou, 1950) embora esse mesmo autor trabalhando com anofelinos do subgênero Kerteszia. no Estado de Santa Catarina, observou demoras de 2 até 18 dias para a eclosão dos ovos de $A$. cruzi. Resultados semelhantes foram encontrados em A. culicifacies onde Ains- 
TABELA VII - Tempo (dias) de aparecimento, término e freqüências absolutas dos estádios imaturos, em relação ao período de oviposição e grau de mortalidade de Anopheles darlingi, em condições experimentais

\begin{tabular}{|c|c|c|c|c|c|c|c|c|}
\hline \multirow{2}{*}{$\begin{array}{l}\text { Dias após a } \\
\text { oviposiçăo }\end{array}$} & \multirow[b]{2}{*}{ Ovos } & \multicolumn{4}{|c|}{ Estádios Larvais } & \multirow[b]{2}{*}{ Pupa } & \multirow[b]{2}{*}{ Adulto } & \multirow[b]{2}{*}{ Mortalidade } \\
\hline & & 1 & II & III & IV & & & \\
\hline 1 & 100 & - & - & - & - & - & - & - \\
\hline 2 & 40 & 60 & - & - & - & - & - & - \\
\hline 3 & - & 100 & - & - & - & - & - & - \\
\hline 4 & - & 87 & 13 & - & - & - & - & - \\
\hline 5 & - & 40 & 58 & 2 & - & - & - & - \\
\hline 6 & - & 7 & 60 & 32 & - & - & - & 1 ( II) \\
\hline 7 & - & - & 32 & 55 & 7 & - & - & $5(\mathrm{II})$ \\
\hline 8 & - & - & 11 & 46 & 35 & - & - & $1($ II); 1 (III) \\
\hline 9 & - & - & 6 & 33 & 50 & - & - & 3 (IV) \\
\hline 10 & - & - & - & 16 & 66 & 4 & - & 2(III):1 (IV) \\
\hline 11 & - & - & - & 9 & 62 & 9 & 1 & 5 (IV) \\
\hline 12 & - & - & - & 4 & 54 & 14 & 7 & 2 (IV) \\
\hline 13 & - & - & - & 1 & 46 & 16 & 13 & 3 (IV) \\
\hline 14 & - & - & - & 1 & 31 & 22 & 21 & 1 (IV) \\
\hline 15 & - & - & - & 1 & 25 & 17 & 31 & 1 (pupa) \\
\hline 16 & - & - & - & - & 19 & 12 & 42 & 1 (pupa) \\
\hline 17 & - & - & - & - & 15 & 5 & 47 & 1(IV):5 (pupa) \\
\hline 18 & - & - & - & - & 12 & 4 & 49 & 2 (pupa) \\
\hline 19 & - & - & - & - & 8 & 6 & 50 & 1 (pupa) \\
\hline 20 & - & - & - & - & 6 & 4 & 53 & 1 (pupa) \\
\hline 21 & - & - & - & - & 4 & 2 & 55 & 2 (pupa) \\
\hline 22 & - & - & - & - & 2 & 3 & 55 & 1 (pupa) \\
\hline 23 & - & - & - & - & - & 2 & 56 & 2 (pupa) \\
\hline 24 & - & - & - & - & - & 1 & 56 & 1 (pupa) \\
\hline 25 & - & - & - & - & - & - & 57 & - \\
\hline$\%$ Mortalidade & - & - & 16,28 & 6,98 & 37,21 & 39,53 & - & 43 \\
\hline \% Sobrevivência & 100 & 100 & 83,72 & 93,02 & 62,79 & 60,47 & - & 57 \\
\hline TOTAL & 100 & 100 & 100 & 100 & 100 & 100 & - & 100 \\
\hline
\end{tabular}


ley (1976) observou um período de 36 a 48 horas para a eclosão dos ovos, com uma taxa de $90 \%$. O mesmo foi observado por Paraluppi (1978) para as primeiras eclosões dos ovos de $A$. nuneztovari. Desta forma, a duração de 1 a 4 dias (média de 2 dias) para a eclosão dos ovos parece estar dentro do esperado.

Os nossos resultados se assemelham, também, aos obtidos por Baily et al. (1979) em A. albimanus, sendo que estes obtiveram uma taxa de eclosão dos ovos mais elevada, alcançando $96 \%$. Portanto, pode considerar-se que fêmeas de $A$. darlingi apresentam um grau de fertilidade relativamente alto, visto que a porcentagem de eclosão dos ovos foi de $75,66 \%$.

A duração dos diferentes estádios larvais de $A$. darlingi não é a mesma. Sem levar em consideração as variaçôes específicas, pode dizer-se que o $2^{\circ}$ e $3 .^{\circ}$ estádios apresentam um tempo de desenvolvimento menor do que o $1^{\circ}$ e $4^{\circ}$ estádios, sendo este último mais longo Resultados semelhantes foram descritos para Aedes aegypti (Christophers, 1960) e para outros culicídeos (Forattini, 1962). É possível que 0 prolongamento do $4{ }^{\circ}$ estádio se deva, em grande parte, às transformaçōes teciduais e morfológicas, acompanhadas de mudanças nos níveis de hormônios destinados à formação do futuro adulto.

Segundo Arias \& Mulla (1975) quando larvas de $1^{\circ}$ estádio de Culex tarsalis são tratadas cum análogos de hormônio juvenil, ocorrem aberraçōes morfológicas, acompanhadas de grande mortalidade no último estádio de larva e de pupa, principalmente entre as ecdises. Desta forma, supõe-se que estas transformações sejam, também, em grande parte, responsáveis pelas maiores taxas de mortalidade que ocorreram no último estádio de larvas e em pupas de $A$. darlingi em condições experimentais. É de esperar-se, por exemplo, que alimentação, fotoperiodismo, temperatura e crescimento de fungos tenham influenciado no desenvolvimento de larvas, contribuindo para o grande índice de mortalidade e maior dura. ção do ciclo vital.

\section{AgRAdECIMENTOS}

Os autores agradecem ao Dr. Jorge R. Árias pelas sugestōes, ao José Marinho Correia pela ajuda nos trabalhos de campo e de laboratório e ao Geraldo Mendes dos Santos pela leitura do manuscrito.

\section{SUMMARY}

Laboratory studies about the biological cycle of Anopheles Darlingi showed that de development from egg to adult is completed in 15.6 days in average, and that the survival rate (from 25 to $28^{\circ} \mathrm{C}$ ) was $57 \%$. The mean number of eggs per female was $110 \pm 50,61$ and the eclosion rate $83,31 \pm 48,21$. Mean eclosion time was estimated in about 2 days. Data regarding the larval and pupal development are also showed.

\section{REFERENCIAS BIBLIOGRÁFICAS}

AINSLEY, R.W.

1976 - Laboratory colonization of the malaria vector, Anopheles culicifacies. Mosq. News, 37: $256-258$.

ARIAS, J.R. \& MULLA, S.

1975 - Morphogenetic aberrations induced by a juvenile hormone analogue in the mosquito Culex tarsalis (Diptera: Culicidae). J. Med. Ent., 12: 309-316.

BARRETO, M.P. \& COUTINHO, J.O.

1943 - Criação de algumas espécies de Anofelinos brasileiros. Rev. Bras. Biol., 3: 317-323.

BAILY, D.L.; FOWLER, J.E.F. \& LOWE, R.E.

1979 - Production efficiency and rate of increase of a massreared laboratory colony of Ano. pheles albimanus Wiedemann. Mosq. News, 39: $640-644$.

BATES, $M$.

1947 - The laboratory colonization of Anopheles darlingi. J. Nat. Malaria Soc., 6 155-158.

CHARLWOOD, J.D. \& HAYES, J.

1978 - Variaçōes geográficas no ciclo de picada do Anopheles darlingi Root no Brasil. Acta Amazonica, 8 (4): 605-611.

CHRISTOPHERS, S.R.

1960 - The larval instars in Aedes aegypti (L.) in: The yellow fever mosquito. Cambridge Univ. Press, Londres. p. 227-249.

COVA-GARCIA, P.

1961 - Descripcion de los huevos de Anofelinos. In: Notas sobre los Anofelinos de Vevezuela y su identificacion. 2. ed Caracas. Ed. Grafos. p. 11-12. 
FERREIRA, E.

1964 - Distribuição geográfica dos Anofelinos no Brasil e sua relaçāo com o estado atual da erradicação da malária. Rev. Bras. Malariol., 16: $329-348$.

FORATTINI, O.P.

1962 - Entomologia médica. Säo Paulo, Faculdade de Higiene e Saúde Pública, vol. 1, 662p.

FREIRE, S.A. \& FARIA, G.S.

1947 - Criação e alguns dados sobre a biologia de Anopheles (N.) darlingi. Rev. Biol., 7: 57.66.

\section{GERBER, E.J.}

1970 - Manual for Mosquito Rearing and Experimental Techniques. Amer. Mosq. Cont. Assoc. Bull., N. ${ }^{\circ}$ 5. 107p.

GORHAM, J.M.; STOJANOVICH, C.J. \& SCOTT, H.G.

1967 - Clave ilustrada para los mosquitos Anofelinos de Sudamérica Oriental U. S. Dept. of Health, Education and Welfare. 64p.

HAYES, J. \& CHARLWOOD, J.D.

1979 - Dinâmica estacional de uma população de Anopheles darlingi numa área endêmica de malária no Amazonas. Acta Amazonica, 9: 79-86.

NEWSON, H.D. \& BLANKESLEE, T.E.

1957 - Observations of a Laboratory colony of the Mosquito Culex tritaeniorhynchus Giles. Mosq. News, 17: 308-311.

PARALUPPI, N.D.

1978 - Alguns aspectos da Biologia e do comportamento de Anopheles (N.) nuneztovari Ga- baldon. (Diptera: Culicidae) dos arredores da cidade de Manaus, Amazonas, Brasil. Dissertação de Mestrado. Manaus, INPA/ FUA. 62p.

RABBANI, M.G.; SEAWRIBHT, J.A. \& LEATHERWOOD, L.B. 1976 - A method for culturing single families of Anopheles albimanus. Mosq. News, 36: 100-102.

RACHOU, R.

1950 - Observações sobre o ciclo evolutivo dos Anofelinos do subgênero Kerteszia em laboratório: fase de ovo. Res. Bras. Malarial. D. Trop., 2: 111-118.

1958 - Algumas manifestaçōes de resistência do comportamento de insetos aos inseticidas no Brasil. Rev. Bras. Malarial. D. Trop., 10: 277-290.

RESENDE, J.N.

1969 - Chave para o subgênero Nyssorhynchus. In: Chave para os subgêneros de Anopheles do Brasil baseada nos caracteres das larvas. Campanha de Erradicação da Malária.

ZULUETA, J. \& BATES, M.

1948 - Laboratory experiments with selection of oviposition site by Anopheles darlingi. Amer. J. Hyg., 48: 350-360.

(Aceito para publicação em $13 / 03 / 81$ ) 